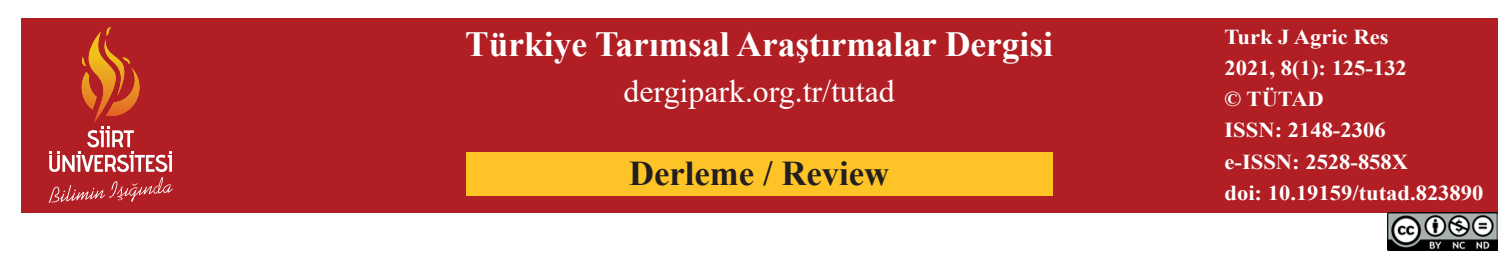

\title{
Vis-NIR ve pXRF Spektrometrelerinin Toprak Biliminde Kullanımı
}

\author{
Gafur GÖZÜKARA*
}

Eskişehir Osmangazi Üniversitesi, Ziraat Fakültesi, Toprak Bilimi ve Bitki Besleme Bölümü, Eskişehir, TÜRKİYE

\begin{abstract}
Geliş Tarihi/Received: 10.11 .2020
Kabul Tarihi/Accepted: 10.02 .2021

ORCID II

(D) orcid.org/0000-0003-0940-5218

Sorumlu Yazar/Corresponding Author: ggozukara@ogu.edu.tr

Öz: Toprakların geleneksel yöntemler ile yapılan fiziksel ve kimyasal analizleri genellikle zaman, maliyet ve kimyasal atık çıktıları nedeniyle çevreye ve ekonomiye bazı dezavantajlar getirmektedir. Bu araştırmanın amacı, i-) toprak biliminde görünür yakın kızılötesi yansıma spektroskopisi (Vis-NIR) ve portatif X ışını floresansı (pXRF) spektralarının giderek yaygınlaşan kullanım alanlarını belirlemek, ii-) Vis-NIR ve pXRF spektralarının toprak biliminde kullanılabilecek alanların ve Vis-NIR ve pXRF spektralarından elde edilen etkinliğin artıılmasına katkı sağlamaktır. Vis-NIR ve pXRF spektrasının toprakların geleneksel fiziksel ve kimyasal analiz metotlarına göre üstünlükleri; çevre dostu, düşük maliyetli, herhangi bir kimyasal maddeye ihtiyaç olmaması, toprak örneklerine zarar vermeden hızlı sonuç alınmasıdır. $\mathrm{Bu}$ nedenle toprak özelliklerinin belirlenmesinde ve tahmin edilmesinde giderek artan oranda kullanılmaktadır. Vis-NIR ve pXRF spektras1; toprakların kum, silt ve kil içeriğinin, organik karbon, organik madde, kireç, nem içeriği, katyon değișim kapasitesi ve pH'nın tahmin edilmesinde yaygın bir şekilde kullanılmaktadır. Araştırmacılar toprak özelliklerinin belirlenmesi ve tahmin edilmesinde Vis-NIR ve pXRF spektrasının bireysel ve birlikte kullanımlarında oldukça başarılı olduklarını rapor etmișlerdir. Vis-NIR ve pXRF spektrasının toprak biliminde kullanım alanlarının genişletilmesi için farklı ana materyal, arazi kullanımı, iklim ve bitki örtüsü altında gelișen topraklarda daha fazla araștırmalar yapılarak yöntemin ve cihazların kalibrasyonlarının geliştirilmesi gerekmektedir. Böylelikle Vis-NIR ve pXRF spektraları ile toprak özelliklerinin tahmin ve karakterize edilmesinde başarı performansının artacağı öngörülmektedir.
\end{abstract}

Anahtar Kelimeler: Vis-NIR, pXRF, toprak bilimi, toprak spektrası, toprak özellikleri

\section{Use of Vis-NIR and pXRF Spectrometers in Soil Science}

\begin{abstract}
Physical and chemical analysis of soils with traditional methods usually brings some disadvantages to the environment and economy due to time, cost, and chemical waste outputs. The purpose of this research were to i-) determine the increasingly widespread usage areas of visible near-infrared reflection spectroscopy (Vis-NIR) and portable X-ray fluorescence (pXRF) spectra in soil science, ii-) contribute to the increasing the efficiency of Vis-NIR and pXRF spectra and the areas that can be used in soil science for Vis-NIR and pXRF spectra. The advantages of Vis-NIR and pXRF spectra over traditional physical and chemical analysis methods of soils are that they are environmentally friendly, low cost, no need for any chemical substance, and rapid results without damaging soil samples. Therefore, it is increasingly used in characterizing and predicting soil properties. Vis-NIR and pXRF spectra have been widely used to predict the content of sand, silt and clay, organic carbon, organic matter, lime, moisture content, cation exchange capacity, and $\mathrm{pH}$ of soils. The researchers reported that Vis-NIR and pXRF spectra were very successful in their individual and combined use in determining and predicting soil properties. To expand the usage areas of Vis-NIR and pXRF spectra in soil science, it is necessary to develop the method and the calibrations of the devices by making more researches in the developing soils under different main materials, land use, climate, and vegetation. Thus, it is predicted that the success performance in the prediction and characterization of soil properties with Vis-NIR and pXRF spectra will increase.
\end{abstract}

Keywords: Vis-NIR, pXRF, soil science, soil spectra, soil properties 


\section{Giriş}

Bir ülkenin en büyük güvencesi olan gida güvenliğinin sağlanması, başta doğal kaynaklarının akılcı ve sürdürülebilir kullanılması ile mümkün olmaktadır. Doğal kaynakların en önemlilerinden birisi olan toprağın akılcı kullanımı ise tarımsal güvenceyi garanti altına almaktadır. Türkiye, farklı iklim ve ekolojik bölgeleri ile tarımsal üretim potansiyeli oldukça yüksek olan bir toprak çeşitliliğine sahiptir. Bununla birlikte ülke topraklarının başta eğim ve erozyon olmak üzere aşırı ve/veya hatalı arazi kullanımı, kirlilik ve tuzluluk gibi çeşitli sorunları da bulunmaktadır. İşte bu nedenle özellikle bitkisel üretim potansiyelleri kısıtlı ya da sınırlı olan alanların doğru ve sürdürülebilir kullanılması çok daha büyük bir önem taşımaktadır. Doğru ve sürdürülebilir arazi kullanımları ise ancak o alana ait ekolojik veri ve bilgilerin varlığ doğruluğu ile mümkün olabilecektir. Özellikle toprakların fiziksel, kimyasal ve biyolojik özelliklerinin bilinmesi toprakların potansiyel kullanım alanlarını ve kısıtlamalarının her koşulda yönetilmesi için büyük önem arz etmektedir (Özyazıcı ve ark., 2015, 2016, 2017; Gözükara ve ark., 2020a, 2020b).

Toprak oluşumu ve gelişimi için zaman, mekan, iklim ve topoğrafya, toprakların özelliklerini ve onların ayrışma oranlarını belirler. Bu etki zamanla morfolojik, fiziksel, kimyasal ve mineralojik özelliklerin değişimi ve gelişimi ile toprak yüzeyinde (yatay) ve toprak profillerinde (dikey) toprak özelliklerin farklılaşmasına neden olur (Sarı ve ark., 2003; Mutlu, 2010; Altunbaş ve Sarı, 2011; Gözükara, 2019; Gözükara ve ark., 2019). Toprak bilimcileri arazi koşullarında renk, tekstür, doku, gözeneklilik, kıvam, kireç ve redoksimorfik görünümler gibi özellikleri pedolojik deneyimleri ölçüsünde yorumlayarak toprak özelliklerini tespit etmeye çalışırlar (Hızalan 1969; Anonymous, 1993; Arnold ve Eswaran, 1993; Dinç ve Şenol, 2013; Gözükara, 2019). Laboratuvar koşullarında ise uluslararası geçerliliği olan geleneksel yöntemler ile toprakların fiziksel ve kimyasal analizleri yapılmaktadır. Fakat laboratuvar koşullarında yapılan toprak araştırmaları ve fiziksel-kimyasal analizleri genellikle zaman, maliyet ve ayn zamanda kimyasal atık çıktılarından dolayı çevre ve ekonomi üzerinde bazı dezavantajlar getirmektedir (Waiser ve ark., 2007; Viscarra Rossel ve ark., 2010). Bu nedenlerle, araştırmacılar çevre dostu, maliyeti düşük, hızlı, toprak örneklerine zarar vermeyen, güvenilir analiz ve ölçüm sonuçlarına ulaşabilecek teknik, teknoloji ve yaklaşımlar üzerindeki çalışmalarını yoğunlaştırmışlardır.
$\mathrm{Bu}$ arayışların sonucunda toprak bilimi alanında toprak algilayıcıların (proximal soil sensing) kullanımı önemli ölçüde artış göstermiştir. Özellikle, görünür yakın kızılötesi yansıma spektroskopisi (Vis-NIR) ve portatif X floresansı (pXRF) spektrası ölçümleri, toprakların geleneksel fiziksel ve kimyasal analiz metotları ile kıyaslandığında çevre dostu, düşük maliyetli, herhangi bir kimyasal maddeye ihtiyaç duymayan, toprak örneklerine zarar vermeyen ve hızlı sonuç alınan bir yöntem olması nedeniyle toprak özelliklerinin belirlenmesi ve tahmin edilmesinde giderek artan oranda kullanılmaktadır (Taylor ve ark., 2004; Waiser ve ark., 2007; Viscarra Rossel ve ark., 2010; Viscarra Rossel ve Webster, 2011; Rouillon ve Taylor, 2016).

$\mathrm{Bu}$ araştırmalar sonucunda ise toprağın bazı fiziksel ve kimyasal özelliklerinin bu teknik ve teknolojiler yardımı ile ekonomik, hızlı ve yüksek doğruluk ile belirlenebileceklerini ifade etmişlerdir (Weindorf ve ark., 2012a; Fajardo ve ark., 2016; Stockmann ve ark., 2016; Zhang ve Hartemink, 2019, 2020). Bu araştırmanın amac1, i-) toprak biliminde Vis-NIR ve pXRF spektralarının giderek yaygınlaşan kullanım alanlarını belirlemek, ii-) VisNIR ve pXRF spektralarının toprak biliminde kullanılabilecek alanların ve Vis-NIR ve pXRF spektralarından elde edilen etkinliğin arttırılmasına katkı sağlamaktır.

\section{Vis-NIR ve pXRF Spektrasının Toprak Biliminde Kullanımı}

Toprakların fiziksel, kimyasal ve biyolojik özelliklerinin bilinmesi toprakların potansiyel kullanım alanlarını ve kısıtlamalarının her koşulda yönetilebilmesi açısından büyük önem arz etmektedir. Bu nedenle fizik, bilgisayar ve uzaktan algılama bilim ve teknolojisinden yararlanılarak ortaya çıkan Vis-NIR ve pXRF spektraları geliştirilmiş ve kullanım alanları toprak örnekleri üzerinde de denenmeye başlanılmıştır. Bilhassa bazı toprak özelliklerinin belirlenmesindeki başarı, diğer toprak özelliklerinin de bu yöntemle hızlı ekonomik ve çevreye duyarlı şekilde kullanılabileceği ihtimalini ortaya çıkarmış ve toprak alanında çalışan bazı uzmanlar bu konuda araştırmalar yürütmeye başlamıştır.

\subsection{Vis-NIR ve toprak biliminde kullanımı}

Dünyada 1900'lü yılların başlarında temel yaklaşımları ortaya çıkan ve özellikle son 20 yıldır artan oranda aktif olarak kullanılan görünür, orta ve yakın kızılötesi spektroskopi (Vis-NIR) teknolojisi toprak özellikleri ve onların dağılımları hakkında bilgi edinmeye farklı bir bakış açısı kazandırmıştır. 
$\mathrm{Bu}$ teknik yaklaşım ve teknoloji ile birlikte, görünür, orta ve yakın kızılötesi dalga boyu aralıklarındaki 1şınımların toprakların yüzeylerindeki farklı molekül, atom ve farklı iyon dağılımlarına bağlı olarak toprakların fiziksel ve kimyasal bileşimleri hakkında hızlı, doğru ve düşük maliyetlerle veri toplayacağ 1 düşünülmüş ve hedeflenmiştir. Bu hedef ile birlikte spektroskopi kavramı ortaya çıkmıştır. Toprak spektroskopi, bir örnekteki atom, molekül veya iyonların, enerji düzeyleri arasındaki farklılıklarda toprak tarafından yansitılan veya absorbe edilen spektral reflektansin ölçülmesi ve yorumlayarak anlamlandırılmasıdır (Kılıç ve ark., 1998). Bu kapsamda spektral yansıma değerlerinin elde edilebilmesi için çeşitli donanım ve yazılımlar ile optik kablo, kontak prob, kalibrasyon tableti bileşenlerinden oluşan spektrometreler geliştirilmiştir (Şekil 1).

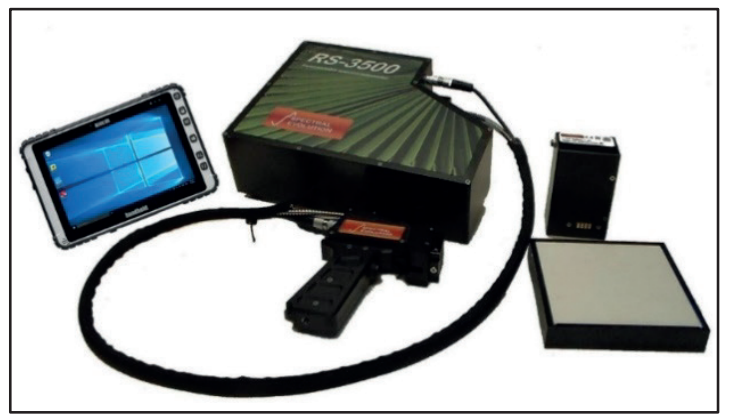

Şekil 1. Görünür-yakın kızılötesi yansıma spektroskopisinin (Vis-NIR) elde edildiği spektrometre ve bileşenleri (donanım, yazılım, optik kablo, kontak prob, kalibrasyon tableti, ve batarya)

(Anonymous, 2020)

Topraklar genellikle farklı jeolojik materyal üzerinde, topoğrafya, iklim koşulları, bitki örtüsü ile zamansal ve mekânsal farklılıkların etkisi altında oluşur ve gelişirler (Gözükara, 2019). Toprak oluşum ve gelişim faktörlerine bağlı olarak farklı fiziksel, kimyasal, biyolojik ve mineralojik özelliklere sahip topraklar ortaya çıkar. Bu farklılıklara bağlı olarak toprakların enerji kullanımında (spektral yansıma) önemli değişiklikler ortaya çıkar. Bilindiği üzere bazı topraklar üzerine gelen enerjiyi önemli ölçüde absorbe ederken (az yansıma), bazı topraklar ise sahip oldukları özelliklere bağlı olarak üzerine gelen enerjinin büyük bölümünü geri yansıtmaktadır. Bu yaklașım sonucunda toprakların görünür, orta ve yakın kızılötesi (Vis-NIR) enerji bölgelerine bağlı spektral imzaları ortaya çıkmaktadır (Şekil 2). Toprakların özelliklerine bağlı olarak gerçekleşen absorbsiyon ve yansıma farklılıkları toprak çeşitlerinin ve toprak özelliklerinin konuma ve zamana bağlı değişkenliklerin tespit ve tahmin edilerek yönetilmesine önemli katkılar sunmaktadır (Benedet ve ark., 2020; Silva ve ark., 2020). Araştırmacıların topraktaki spektral yansıma değerlerinin genellikle i) tekstür, ii) organik madde, iii) mineral bileşim ve iv) nem miktarından önemli ölçüde etkilendiğini belirtmișlerdir (Sarı, 1986; Chen 2002; Zhang ve Hartemink, 2020). Bununla birlikte toprağın heterojen yapıya sahip olması ve toprak içerisindeki süreçlerin karmaşık olması toprakların tam olarak karekterize edilmesini engellemektedir (Viscarra Rossel ve ark., 2006). Toprakların fiziksel ve kimyasal özelliklerinin geleneksel yöntemler ile belirlenmesi aşamasında toprak hazırlığg1, kimyasal kullanımı, zaman kaybı, yüksek maliyet ve analiz sonucunda ortaya çıkan kimyasal atık, su ve cam malzeme sarfiyatı gibi birçok dezavantaja sahiptir. $\mathrm{Bu}$ nedenle toprak özelliklerinin belirlenmesi ve tahmin edilmesi için araştırmacılar günümüze kadar artan oranda VisNIR ve pXRF spektralarını kullanarak bahsi geçen dezavantajların azaltılmasına katkı sağlamışlardır.

Yakın kızılötesi yansıma spektroskopisi (350$2500 \mathrm{~nm}$ arasında) özellikle; toprakların kil, silt ve kum içeriğinin (Waiser ve ark., 2007; Viscarra Rossel ve ark., 2009; Tümsavaş ve ark., 2019; Zhang ve Hartemink, 2020), organik karbon miktarının (Gomez ve ark., 2008; Yorulmaz ve ark., 2017), kireç, nem içeriğinin (Yost ve Hartemink, 2019), katyon değişim kapasitesi ve pH'nın (BenDor ve Banin, 1995; Stockmann ve ark., 2016), agregat stabilitesi ve parçacık dağılımının (Shi ve ark., 2020), toprak renginin (Simon ve ark., 2020) tahmin edilmesinde yaygın bir şekilde kullanılmaktadır.

Tahmin performanslarının yanında, spektral yansıma değerleri ile tuzlu toprakların karakterize edilmesi (Bilgili ve ark., 2010), toprak horizon sınırlarının belirlenmesi (Zhang ve Hartemink, 2019), toprak profillerindeki farklılıkların karakterize edilmesi (Silva ve ark., 2020), toprak profillerindeki farklılıklara bağlı olarak toprakların büyük grup seviyesinde (Soil taxonomy-subgroups) sinıflandirılması (Benedet ve ark., 2020) ve farklı toprak sinıflama sistemlerine göre toprakların sinıflandırılması (Acree ve ark., 2020) üzerinde araştırmalar da yoğunlaşmıştır.

$\mathrm{Ng}$ ve ark. (2019) Vis-NIR spektrası ile toprağın kum içeriğini $\left(\mathrm{R}^{2}=0.60\right)$, kil içeriğini $\left(\mathrm{R}^{2}=0.76\right)$, toplam karbon miktarını $\left(\mathrm{R}^{2}=0.70\right)$ ve $\mathrm{pH}^{\prime} \mathrm{y} 1$ $\left(\mathrm{R}^{2}=0.76\right)$ başarılı bir şekilde tahmin etmişlerdir. Benedet ve ark. (2020) toprak özelliklerini kullanarak Vis-NIR spektrası ile büyük toprak grubunu (Soil Taxonomy) tahmin etmek amaciyla faklı toprak horizonlarından (A ve B horizonları) alınan toprakları karşılaştırmışlardır. Araştırma sonuçlarına göre $\mathrm{B}$ horizonuna ait toprakları 


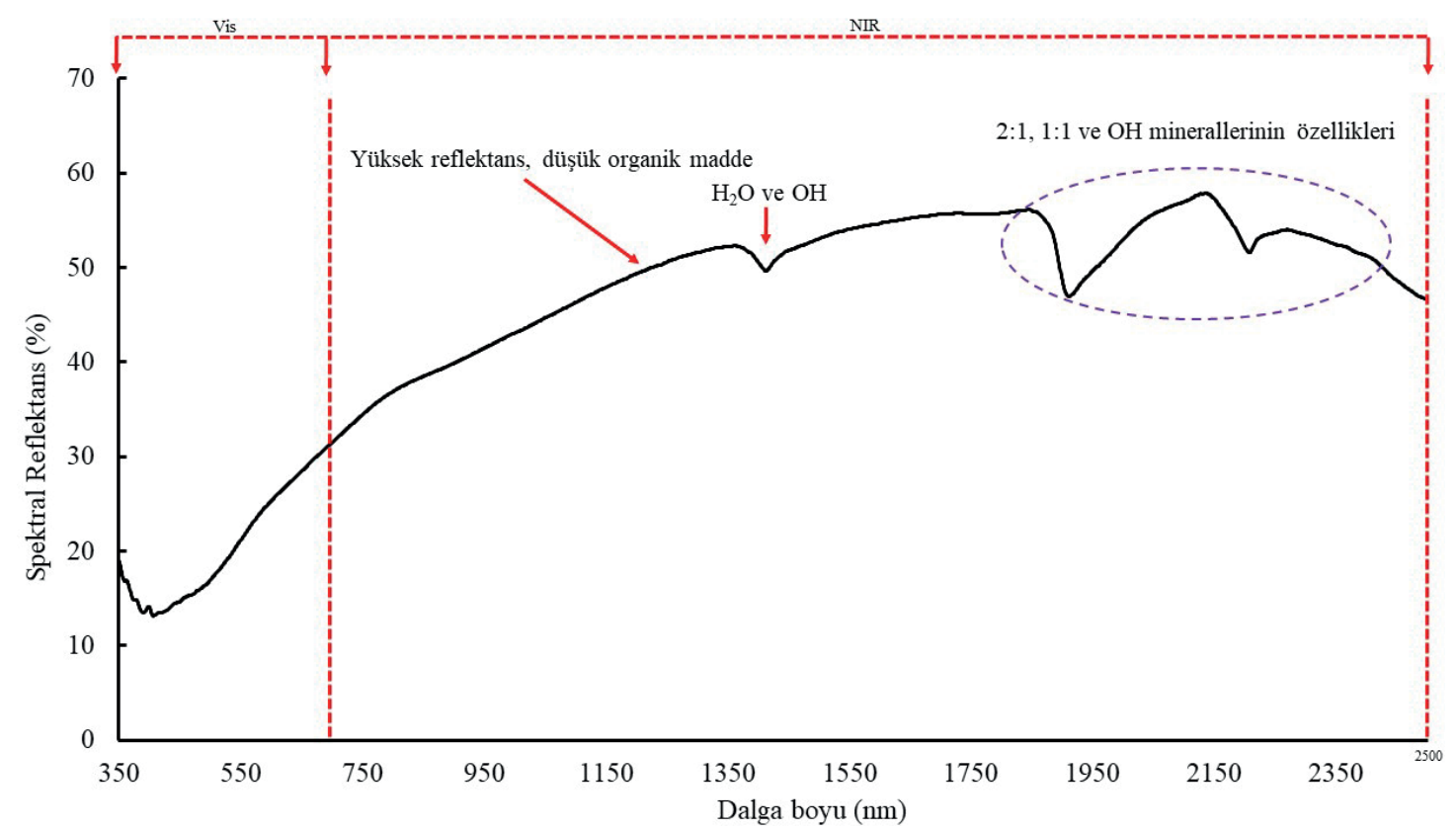

Şekil 2. Farklı dalga boylarına göre toprağın görünebilir dalga boyu bölgesinde (Vis; 350-700 nm) ve yakın infrared (NIR; 700-2500 nm) bölgelerindeki spektral yansıma değerleri

kullanarak büyük toprak grubunun daha başarılı tahmin edildiğini rapor etmişlerdir. Zhang ve Hartemink (2019) toprak örneklerinde kum, silt, kil, toplam karbon (TC) ve pH değerlerinin Vis-NIR spektrası ile tahmin etmek amaciyla toprak özelliklerinin yüksek değişkenlik gösterdiği göl sedimentleri ve buzul çökelleri üzerinde gelişen 25 farklı toprak profilinden alınan topraklar üzerinde horizon farklılıkları ve derinlikleri dikkate alınmadan model oluşturmuşlardır. Araştırma sonucunda kil, silt, kum, TC, toplam azot (TN) içerikleri $\mathrm{R}^{2}=0.41$ ve $\mathrm{R}^{2}=0.61$ arasında değişen tahmin performansiyla belirleyebilirken, $\mathrm{pH}$ değerinin ise tahmin edilemediğini rapor etmiştir. Araştırmacılar özellikle toprak özelliklerindeki farklı ana materyale bağlı yüksek değişkenliğin toprak özelliklerinin Vis-NIR spektrası ile tahmin performanslarını oldukça etkilediğini belirtmişlerdir.

\section{2. $\mathrm{pXRF}$ ve toprak biliminde kullanımı}

X 1şını floresansı (XRF) yöntemi ilk olarak Alman Fizikçi Röntgen tarafından 1891 keşfedilerek kullanılmaya başlanmıştır. Barkla ve Moseley elementler ve atomlar arasındaki ilişkinin kurulmasına katkı sağlayarak X 1şını floresansı alanındaki çalışmalara katkı sağlamışlarıdır (Potts ve West, 2008). Bu katkılar doğrultusunda bugün elementlerin atomik numaralandırılmasına da önemli katkılar sağlamışlardır. XRF spektrası temel olarak enerji ve elementlerin atom numaraları arasındaki ilişkinin tanınması prensibine dayanmaktadır (Potts ve West, 2008). X-1şını floresan yöntemi, analitin tüm içeriğine ve matrise bağlı floresan çıkış hacmine dayalı ölçümler üretir (Ravansari ve Lemke, 2018). Bununla birlikte XRF ile ölçüm yapılan örnekteki toplam element konsantrasyonu ortaya çıkarmaktadır (Hu ve ark., 2014; Sharma ve ark., 2015; Tighe ve ark., 2018). XRF cihazının sadece laboratuvar ortamında ölçüm yapmaya uygun olması portatif olan XRF (pXRF) cihazının yaygın olarak kullanılmasına katkı sağlamıştır.

Şekil 3'te gösterilen pXRF tarımsal üretkenlik, ağır metal içeriği, elemental konsantrasyon, toprakların ayrışma oranı gibi birçok temel alanda kullanım kolaylığı sağlamaktadır (Dao ve ark., 2013; Brown ve ark., 2016; Tighe ve ark., 2018, Zhang ve Hartemink, 2019, 2020; Silva ve ark., 2020). Ayrıca, pXRF kimyasal metotlara göre laboratuvar ve arazide ölçüm kolaylığı, ekonomik, hızlı ve toprak örneklerini tahrip etmeden elementlerin konsantrasyonları ppm ve \% olarak bilgisayar ortamında alınması ve kolay kullanım imkanı sağlamaktadır (Taylor ve ark., 2004; Rouillon ve Taylor, 2016). Bu katkılara bağlı olarak pXRF'nin toprak biliminde analiz cihazı olarak kullanılması ve kabul görmesi her geçen gün ivmelenerek artmaktadır (McLaren ve ark., 2012; Rouillon ve ark., 2017; Ravansari ve Lemke, 2018). pXRF ile elde edilen her bir elementin farkl1 enerji seviyelerinde kendisine özgü bir enerji seviyesi olmasına bağlı olarak elementler ilgili enerji seviyelerine göre kolayca tanımlanabilmektedir. Toprak örneğindeki elementin konsantrasyonu ne kadar fazla ise pXRF'in spektrasındaki piklerde o kadar duyarlı olmaktadır (Şekil 4). 


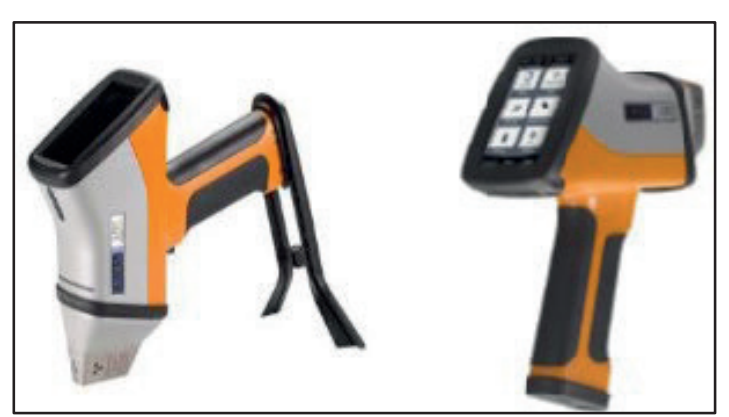

Şekil 3. Portatif X ışını floresansı (pXRF) cihazı

Portatif X-1şını floresansı spektral yansıma ise; toplam karbon miktarının (Zhang ve Hartemink, 2019), organik karbon miktarının (Gomez ve ark., 2008), kil, silt ve kum içeriğinin (Zhu ve ark., 2011; Zhang ve Hartemink, 2020), katyon değişim kapasitesinin (Sharma ve ark., 2015) ve $\mathrm{pH}$ değerinin (Zhang ve Hartemink, 2020) tahmin edilmesinde yaygın bir şekilde kullanılmaktadır.
Tahmin performanslarının yanında pXRF spektral yansıma değerleri ile toprak horizonlarının (albic ve spodic) karakterize edilmesi (Weindorf ve ark., 2012b), toprakların ayrışma oranlarının belirlenmesi (Silva ve ark., 2018; Zhang ve Hartemink, 2019; Yost ve ark., 2019), toprak verimliliğinin belirlenmesi (Andrade ve ark., 2020), toprak tekstürünün karakterize edilmesi (Zhu ve ark., 2011), toprakların ana materyalinin karakterize edilmesi (Mancini ve ark., 2019) gibi farklı alanlarda da pXRF kullanım olanağı sağlamaktadır.

Zhu ve ark. (2011) pXRF spektraları ile elde ettikleri bazı element konsantrasyonları ile çoklu linear regresyon modelini kullanarak toprağın kum $\left(\mathrm{R}^{2}=0.89\right)$, silt $\left(\mathrm{R}^{2}=0.88\right)$ ve kil $\left(\mathrm{R}^{2}=0.98\right)$ içeriklerini oldukça başarılı bir şekilde tahmin etmişlerdir. Andrade ve ark. (2020), toprak örneklerinde TN, katyon değişim kapasitesi (KDK) ve organik madde (OM) miktarının $A$ ve $B$

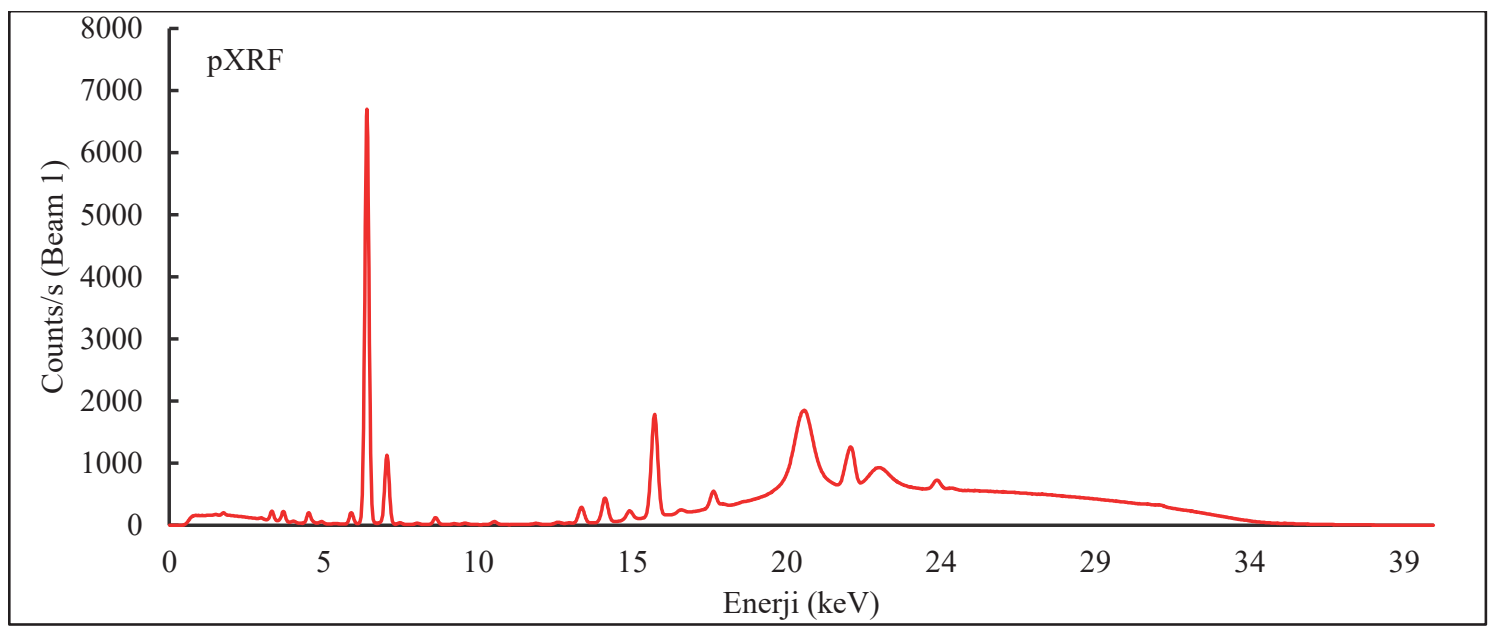

Şekil 4. Farklı enerji (keV) aralıklarına göre toprağın pXRF spektral yansıma değerleri

horizonları topraklarına ait verileri ayırarak pXRF spektrası ile tespit edilebilirliğini araştırmışlardır. Araştırmacılar A ve B horizonlarından alınan toprak örneklerinin birlikte kullanıldıklarında TN miktarının $\left(\mathrm{R}^{2}=0.50\right)$, KDK konsantrasyonun $\left(\mathrm{R}^{2}=0.76\right)$ ve $\mathrm{OM}$ içeriğinin $\left(\mathrm{R}^{2}=0.56\right) \mathrm{pXRF}$ spektrası ile yüksek doğrulukla tespit edildiğini rapor etmişlerdir. Aynı zamanda araştırmacılar tahmin performansının horizon farklılı̆̆ından etkilendiğini bildirmişlerdir. Mancini ve ark. (2019) farklı arazi koşullarında gelişen toprakların A, B ve C horizonlarında pXRF spektrası ve element konsantrasyonu ile farklı ana materyalleri tahmin etmeye çalıșmışlardır. Araştırma sonucunda ana materyalin tahmin edilmesindeki performans üzerine C horizonlarından alına toprak örneklerinde daha yüksek doğruluk performansı (ortalama doğruluk $=0.87$ ve Kappa katsayısı $=0.79)$ elde etmişlerdir.

\section{Sonuç ve Öneriler}

Günümüzde toprakların fiziksel ve kimyasal özelliklerinin belirlenmesinde kamu, özel sektör ve belediyelerde birçok toprak analiz laboratuvarlarında birçoğu yurtdışından ithal edilen pahalı cihazlar, çeşitli kimyasal ve cam malzemeler bulundurulmaktadır. Cihazlarda meydana gelen küçük arızalar dahi oldukça pahalı maliyetlere neden olabilmektedir. Bunun sonucunda ise pek çok laboratuvar, başta ekonomik sebepler olmak üzere, niteliğini kaybetmekte, kapatılmakta ya da atıl hale gelmektedir. Şüphesiz toprak analiz laboratuvarları önemli ve gereklidir. Diğer yandan Türkiye'de henüz toprak özelliklerine dayalı detaylı toprak 
etütleri yapılamamış ve toprak özellikleri sistematik bir şekilde ortaya çıkarılamamıştır. Bu durum yüksek maliyet, zaman ve yetişmiş eleman eksikliğinden kaynaklanmaktadır. Literatür araştırmalarından toprak özelliklerinin tahmin edilmesi ve karakterize edilmesinde Vis-NIR ve pXRF spektralarının bireysel olarak kullanılarak başarılı sonuçların elde edildiği çok net bir şeklide görülmektedir. Vis-NIR ve pXRF spektrasının toprakların geleneksel fiziksel ve kimyasal analiz metotları ile kıyaslandığında çevre dostu, düşük maliyetli, herhangi bir kimyasal maddeye ihtiyaç olmaması, toprak örneklerine zarar vermeden sonuç alınması ve hızl olmasından dolayı toprak özelliklerinin belirlenmesi ve tahmin edilmesinde giderek artan oranda kullanılması güvenilir bir analiz yöntemi olduğu göstermektedir.

Başarı performansını artırmak için toprak oluşum faktörlerinin dikkate alındığı, farklı ana materyal, topoğrafya, iklim, canlılar ve zaman içerisinde gelişen, genetik değişim ve dönüşümler yaşayarak karakterize olan çok sayıda toprak örneğinde daha fazla araştırmalar yapılarak yöntemin ve cihazların kalibrasyonların geliştirilmesi gerekmektedir. Böylelikle Vis-NIR ve pXRF spektraları ile toprak özelliklerinin tahmin ve karakterize edilmesinde başarı performansının artacağ1, arazi kullanım planlaması, arazi toplulaştırma gibi büyük yatırımlarda da ülke ekonomisine katk1 sağlayacağı düşünülmektedir.

\section{Kaynaklar}

Acree, A., Weindorf, D.C., Paulette, L., Gestel, N.V., Chakraborty, S., Man, T., Jordan, C., Prieto, J.L., 2020. Soil classification in Romanian catenas via advanced proximal sensors. Geoderma, 377: 114587.

Altunbaş, S., Sarı, M., 2011. Kurutulan kestel gölünden kazanılan toprakların bazı özellikleri ile üretim potansiyelleri arasındaki ilişkiler. Akdeniz Üniversitesi Ziraat Fakültesi Dergisi, 24(1): 61-65.

Andrade, R., Faria, W.M., Silva, S.H.G., Chakraborty. S., Weindorf. D.C., Mesquita., L.F., Guilherme, L.R.G, Curi, N., 2020. Predcition of soil fertility via portable $\mathrm{X}$-ray fluorescence (pXRF) spectrometry and soil texture in the Brazilian Coastal Plains. Geoderma, 357: 113960 .

Anonymous, 1993. Soil Survey Division Staff, Soil Survey Manual. USDA Handbook 18, Washington DC.

Anonymous, 2020. Field Portable NIR Spectroradiometers for Remote Sensing. (https://spectralevolution.com), (Erişim tarihi: 15.09.2020).

Arnold, R., Eswaran, H., 1993. Soil horizon use by the US soil survey. Catena, 20: 375-381.

Ben-Dor, E., Banin, A., 1995. Near-infrared analysis as a rapid method to simultaneously evaluate several soil properties. Soil Science Society of America Journal, 59(2): 364-372.

Benedet, L., Faria, W.M., Silva, S.H.G., Mancini, M., Guilherme, L.R.G., Demattê, J.A.M., Curi, N., 2020. Soil subgroup prediction via portable X-Ray fluorescence and visible near-infrared spectroscopy. Geoderma, 365: 114212.

Bilgili, A.V., Vas Es, H.M., Akbas, F., Durak, A., Hively, W.D., 2010. Visible-near infrared reflectance spectroscopy for assessment of soil properties in a semi-arid area of Turkey. Journal of Arid Environments, 74: 229-238.

Brown, S.L., Chaney, R.L., Hettiarachchi, G.M., 2016. Lead in urban soils: a real or perceived concern for urban agriculture? Journal of Environmental Quality, 45(1): 26-36.

Chen, X., 2002. Using remote sensing and GIS to analyze land cover change and its impact on regional sustainable development. International Journal of Remote Sensing, 23(1): 107-124.

Dao, L., Morrison, L., Kiely, G., Zhang, C., 2013. Spatial distribution of potentially bioavailable metals in surface soils of a contaminated sports ground in Galway, Ireland. Environmental Geochemistry Health, 35(2): 227-238.

Dinç, U., Şenol, S., 2013. Toprak Etüd ve Haritalama. Çukurova Üniversitesi, Ziraat Fakültesi Genel Yayın No: 161, Ders Kitapları Yayın No: A-50, Çukurova Üniversitesi Ziraat Fakültesi Ofset Atölyesi, Adana.

Fajardo, M., McBratney, A., Whelan, B., 2016. Fuzzy clustering of Vis-NIR spectra for the objective recognition of soil morphological horizons in soil profiles. Geoderma, 263: 244-253.

Gomez, C., Viscarra Rossel, R.A., McBratney, A.B., 2008. Soil organic carbon prediction by hyperspectral remote sensing and field vis-NIR spectroscopy: An Australian case study. Geoderma, 146: 403-411.

Gözükara, G., 2019. Eski göl tabanlarındaki zamansal ve mekansal değişimlerin toprak oluşumuna etkileri: Burdur göl havzası örneği. Doktora tezi, Akdeniz Üniversitesi, Fen Bilimleri Enstitüsü, Antalya.

Gözükara, G., Altunbaş, S., Sarı, M., 2019. Mekansal değişimin alüviyal fanlar üzerinde oluşan toprakların özelliklerine etkisi. Mediterranean Agricultural Sciences, 32(3): 425-435.

Gözükara, G., Altunbaş, S., Sarı, M., 2020a. Zamansal ve mekansal değişimlerin farklı fizyoğrafyalardaki toprak oluşumu, gelişimi ve morfolojisi üzerine etkisi. Ege Üniversitesi Ziraat Fakültesi Dergisi, 57(2): 277-278

Gözükara, G., Altunbaş, S., Sarı, M., 2020b. Zamansal ve mekansal değişimlerin eski göl tabanlarındaki toprak oluşumu, gelişimi ve morfolojisi üzerine etkisi. Harran Tarım ve Gida Bilimleri Dergisi, 24(1): 96110.

Hizalan, E., 1969. Toprak Etüt ve Haritalama I. Ankara Üniversitesi, Ziraat Fakültesi Yayınları No: 379, Ankara.

Hu, W., Huang, B., Weindorf, D.C., Chen, Y., 2014. Metals analysis of agricultural soils via portable $\mathrm{X}$ - 
ray fluorescence spectrometry. Bulletin of Environmental Contamination and Toxicology, 92(4): 420-426.

Kılıç, E., Köseoğlu, F., Yılmaz, H., 1998. Enstrümental Analiz İlkeleri. Bilim Yayıncılık, Kızılay, Ankara.

Mancini, M., Weindorf, D.C., Chakraborty, S., Silva, S.H.G., Teixeira, A.F.S., Guilherme, L.R.G., Curi, N., 2019. Tracing tropical soil parent material analysis via portable X-ray fluorescence ( $\mathrm{pXRF}$ ) spectrometry in Brazilian Cerrado. Geoderma, 337: 718-728.

McLaren, T.I., Guppy, C.N., Tighe, M.K., Forster, N., Grave, P., Lisle, L.M., Bennett, J.W., 2012. Rapid, nondestructive total elemental analysis of vertisol soils using portable Xray fluorescence. Soil Science Society of America Journal, 76(5): 1436-1445.

Mutlu, H.H., 2010. Eski konya gölü kuvaterner terasları üzerinde oluşan toprakların jeokimyasal özellikleri ve ayrışma oranları. Yüksek lisans tezi, Selçuk Üniversitesi, Fen Bilimleri Enstitüsü, Konya.

Ng, W., Minasny, B., Montazerolghaem, M., Padarian, J., Ferguson, R., Bailey, S., McBratney, A.B., 2019. Convolutional neural network for simultaneous prediction of several soil properties using visible/near-infrared, mid-infrared, and their combined spectra. Geoderma, 352: 251-267.

Özyazıcı, M.A., Dengiz, O., Aydoğan, M., Bayraklı, B., Kesim, E., Urla, Ö., Yıldız, H., Ünal, E., 2015. Orta ve Doğu Karadeniz Bölgesi tarım topraklarının bazı makro ve mikro bitki besin maddesi konsantrasyonları ve ters mesafe ağırlık yöntemi (IDW) ile haritalanmas1. Artvin Çoruh Üniversitesi Orman Fakültesi Dergisi, 16(2): 187-202.

Özyazıcı, M.A., Dengiz, O., Aydoğan, M., Bayraklı, B., Kesim, E., Urla, Ö., Yıldız, H., Ünal, E., 2016. Orta ve Doğu Karadeniz Bölgesi tarım topraklarının temel verimlilik düzeyleri ve alansal dağılımları. Anadolu Tartm Bilimleri Dergisi, 31(1): 136-148.

Özyazıcı, M.A., Dengiz, O., Özyazıcı, G., 2017. Spatial distribution of heavy metals density in cultivated soils of Central and East Parts of Black Sea Region in Turkey. Eurasian Journal of Soil Science, 6(3): 197205.

Potts, P.J., West, M., 2008. Portable X-ray fluorescence spectrometry. In: P.J. Potts, M. West (Eds.), Capabilities for in Situ Analysis, 1st Edn., RSC Publising, Sheffield, pp. 83-97.

Ravansari, R., Lemke, L.D., 2018. Portable X-ray fluorescence trace metal measurement in organic rich soils: pXRF response as a function of organic matter fraction. Geoderma, 319: 175-184.

Rouillon, M., Taylor, M.P., 2016. Can field portable Xray fluorescence ( $\mathrm{pXRF}$ ) produce high quality data for application in environmental contamination research? Environmental Pollution, 214: 255-264.

Rouillon, M., Taylor, M.P., Dong, C., 2017. Reducing risk and increasing confidence of decision making at a lower cost: In-situ pXRF assessment of metalcontaminated sites. Environmental Pollution, 229: 780-789.
Sar1, M., 1986. Uzaktan Algılamada Gözle Yapılan Yorumlamalar ve Bilgi Üretimi: Toprak. Uzaktan Algılama Lisans Üstü Yaz Okulu Ders Notu, Çukurova Üniversitesi Fen Bilimleri EnstitüsüTÜBİTAK-TUFUAB, Adana.

Sarı, M., Altunbaş, S., Sönmez, N.K., Emrahoğlu, E. 2003. Farklı fizyografik üniteler üzerinde yer alan eski Manay göl alanı topraklarının özellikleri ve potansiyel üretkenlikleri. Akdeniz Üniversitesi Ziraat Fakültesi Dergisi, 16(1): 7-17.

Sharma, A., Weindorf, D.C., Wang, D., Chakraborty, S., 2015. Characterizing soils via portable X-ray fluorescence spectrometer: 4. Cation exchange capacity (CEC). Geoderma, 239-240: 130-134.

Shi, P., Castaldi, F., Wesemael, B.V., Ooast, K.V., 2020. Vis-NIR spectroscopic assessment of soil aggregate stability and aggregate size distribution in the Belgium loam belt. Geoderma, 357: 113958.

Silva, S.H.G., Hartemink, A.E., Teixeira, A.F.S., Inda, A.V., Guilherme, L.R.G., Curi, N., 2018. Soil weathering analysis using a portable X-ray fluorescence (PXRF) spectrometer in an inseptisol from the Brazilian Cerrado. Applied Clay Science, 162: $27-37$.

Silva, S.H.G., Weindorf, D.C., Pinto, L.C., Faria, W.M., Acerbi Junior, F.W., Gomide, L.R., Mello, J.M., Pádua Junior, A.L., Souza, I.A., Teixeira, AFS., Guilherme, L.R.G., Curi. N., 2020. Soil texture prediction in tropical soils: a portable Xrayfluorescencespectrometry approach. Geoderma, 362: 114136.

Simon, T., Zhang, Y., Hartemink, E.A., Huang, J., Walter, C., 2020. Predicting the color of sandy soils from Wisconsin, USA. Geoderma, 361: 114039.

Stockmann, U., Cattle, S.R., Minasny, B., McBratney, A.B., 2016. Utilizing portable X-ray fluorescence spectrometry for in-field investigation of pedogenesis. Catena, 139: 220-231.

Taylor, P.D., Ramsey, M.H., Potts. P.J., 2004. Balancing measurement uncertainty against financial benefits: comparison of in situ and ex situ analysis of contaminated land. Enviromental Science and Technology, 38(24): 6824-6831.

Tighe, M., Rogan, G., Wilson, S.C., Grave, P., Kealhofer, L., Yukongdi, P., 2018. The potential for portable Xray fluorescence determination of soil copper at ancient metallurgy sites, and considerations beyond measurements of total concentrations. Journal of Environmental Management, 206: 373-382.

Tümsavaş, Z., Tekin, Y., Ulusoy, Y., Mouazen, A.M., 2019. Prediction and mapping of soil clay and sand contents using visible and near-infrared spectroscopy. Biosystems Engineering, 177: 90-100.

Viscarra Rossel, R.A., Cattle, S.R., Ortega, A., Fouad, Y., 2009. In situ measurements of soil colour, mineral composition and clay content by viseNIR spectroscopy. Geoderma, 150: 253-266.

Viscarra Rossel, R.A., McBratney, A.B., Minasy, B., 2010. Proximal Soil Sensing. Springer, New York.

Viscarra Rossel, R.A., Walvoort, D.J.J., McBratney, A.B., Janik, L.J., Skjemstad. J.O., 2006. Visible, near 
infrared, mid infrared or combined diffuse reflectance spectroscopy for simultaneous assessment of various soil properties. Geoderma, 131: 59-75.

Viscarra Rossel, R.A., Webster, R., 2011. Discrimination of Australian soil horizons and classes from their visible near infrared spectra. European Journal of Soil Science, 62(4): 637-647.

Waiser, T.H., Morgan, C.L.S., Brown, D.J., Hallmark, C.T., 2007. In situ characterization of soil clay content with visible near-infrared diffuse reflectance spectroscopy. Soil Science Society of America Journal, 71(2): 389-396.

Weindorf, D.C., Zhu, Y., Haggard, B., Lofton, J., Chakraborty, S., Bakr, N., Zhang, W., Weindorf, W.C., Legoria, M., 2012a. Enhanced pedon horizonation using portable Xray fluorescence spectrometry. Soil Science Society of America Journal, 76(2): 522-531.

Weindorf, D.C., Zhu, Y., McDaniel, P., Valerio, M., Lynn, L., Michaelson, G., Ping, C.L., 2012 b. Characterizing soils via portable X-ray fluorescence spectrometer: 2. Spodic and Albic horizons. Geoderma, 189-190: 268-277.
Yorulmaz, A., Aydın, G., Atatanır, L., 2017. Determination of soil organic carbon levels using near infrared spectroscopy (NIRS) in Saline Soils. Adnan Menderes Üniversitesi Ziraat Fakültesi Dergisi, 14(2): 29-31.

Yost, J.L., Roden, E.E., Hartemink, A.E., 2019. Geochemical fingerprint and soil carbon of sandy alfisols. Soil Systems, 3(3): 59.

Yost, J.L., Hartemink, A.E., 2019. Effect of carbon on mousture storage in soils of the Wisconsin Central Sands, USA. European Journal of Soil Science, 70(3): 565-577.

Zhang, Y., Hartemink, A.E., 2019. Soil Horizon Delineation Using Vis-NIR and pXRF data. Catena, 180: 298-308.

Zhang, Y., Hartemink, A.E., 2020. Data fusion of vis-nır and pxrf spectra to predict soil physical and chemical properties. European Journal of Soil Science, 71(3): 316-333.

Zhu, Y., Weindorf, D.C., Zhang, W., 2011 Characterizing soils using a portable X-ray fluorescence spectrometer: 1. Soil texture. Geoderma, 167-168: 167-177. 